\title{
Características léxico-semánticas de las crónicas futbolísticas del Real Madrid en el diario Marca
}

\section{Lexical and semantic characteristics of the football chronicles of Real Madrid in the newspaper Marca}

\author{
Antonio María López González \\ Uniwersytet Łódzki \\ antonio.lopez@uni.lodz.pl
}

\begin{abstract}
Within the sports language, the lexical level is composed of slang, specialized terminology and figurative lexicon. This work analyzes the lexical-semantic characteristics of the football language in a corpus of news chronicles of Real Madrid football matches, published on the web site marca.com. We focus on the fundamental lexicon of these chronicles, as well as on the core concepts of them, their designations and the means of meaning.
\end{abstract}

Keywords: sports press, football language, lexicon, terminology, metaphor

\section{EL LENGUAJE DEPORTIVO Y EL LÉXICO FUTBOLÍSTICO}

El nivel léxico es, sin duda, el más característico del lenguaje de la prensa deportiva. Con una selección de palabras siempre intencional, los textos periodísticos se componen tanto de "palabras que satisfacen funciones comunes de todos los hablantes de la lengua y sirven, por tanto, a toda practica lingüística particular", como de "palabras que sirven a funciones o tareas sociales específicas y son usadas reservadamente en ambientes, situaciones o contextos sociales determinados" (Núñez Ladeveze 1991: 132). Las palabras de este segundo tipo son las que pertenecen a las lenguas especiales, como la lengua del fútbol, que se especializa en la designación de contenidos en el área de este deporte. 
Según Hernández Alonso (2003: 57), el 60\% del léxico de la prensa deportiva se puede considerar común o estándar, en tanto que el $40 \%$ tiene, realmente, una particularidad deportiva propia. A su vez, dentro de este $40 \%$ de léxico propiamente deportivo - aquí futbolístico - se distinguen los siguientes grupos léxicos (Hernández Alonso 2003: 58 y ss.).

1. Léxico argótico (7\%): Son palabras y expresiones propias del fútbol, muchas de ellas ya con "una clara penetración en el español coloquial" (Naranjo de Arcos 2011: 94), que se han trasladado y se utilizan en otros ámbitos de la vida social, dada la popularidad de este deporte. Entre estos términos se cuentan: "hacer un caño (introducir el balón entre las piernas del contrario para librarse de este jugador y continuar la carrera), tocar (pasar la pelota con suavidad al compañero), gol cantado (fallar una ocasión muy clara) y vacas sagradas (expresión para referirse a los jugadores estrella del equipo)" (Álvarez Pedrosa 2017: 60).

2. Léxico técnico-especializado (12\%): Se trata de un léxico especializado, de carácter internacional, con origen en la reglamentación del deporte. En este léxico predomina la denominación y la monosemia, con grandes aportaciones de neologismos y préstamos. Son tecnicismos: driblar, libre directo, desmarque, saque de banda, fuera de juego, etc. Entre los neologismos los hay: por derivación, cabecear, colista, colchonero; por composición, azulgrana, centro-chut, mediapunta; por siglas, LFP, VAR, UEFA, etc. Son extranjerismos: córner, club, gol, linier, penalti, amateur, debut, tifo, etc. (Aleixandre-Benavent et al. 2007).

3. Léxico trasladado (21\%): Es el léxico más empleado en las crónicas deportivas. Por medio de los usos trasladados, palabras habitualmente empleadas en campos ajenos al deporte (guerra, ciencia y técnica, religión, sabiduría popular, etc.) se trasladan al campo deportivo. Los principales recursos de traslación son la metáfora, la sinécdoque, la polisemia y la sinonimia. Entre estos campos semánticos destaca el lenguaje belicista, por la dimensión de rivalidad y enfrentamiento del deporte, con palabras como cañonazo, disparo, enemigo, ataque, víctima, peligro, dinamita, pólvora, ariete (Esteve y Fernández 1999).

\section{METODOLOGÍA DEL ANÁLISIS}

La crónica deportiva de fútbol es el género periodístico más representativo de la prensa deportiva española. Completada con marcadores, datos estadísticos y declaraciones, la crónica futbolística sintetiza y analiza el partido de fútbol de un modo cronológico, explicando los lances del juego y valorando la actuación individual de los jugadores, entrenadores o de los equipos contrincantes.

Este trabajo analiza el léxico de dichas crónicas deportivas, con un doble objetivo. Primero identifica los conceptos recurrentes en las crónicas de fútbol. Después, indaga en la expresión léxica de esos conceptos y en su modo de significar. 
El corpus objeto de estudio está formado por 18 crónicas periodísticas de partidos de fútbol, tomadas de la versión digital del diario Marca. Tanto en su versión en papel como en su versión digital, Marca es el periódico más leído de España, según el Estudio General de Medios (E.G.M.). En el periodo estudiado, el sitio de internet del diario Marca fue la web de información deportiva más visitada de España, pasando de 3089000 visitantes diarios en la edición de octubre-noviembre de 2009 del E.G.M., a 4788000 visitantes en la edición de marzo-mayo de 2018 del E.G.M.

En el diseño del corpus, las crónicas se restringen al mismo equipo y el mismo estadio. Por su representatividad y repercusión mediática, la elección recae en el Real Madrid y en su estadio el Santiago Bernabéu. El equipo visitante es siempre diferente.

El corpus analizado está formado por 18 crónicas deportivas. Estas fueron tomadas al azar, una por cada vuelta de cada temporada - 2009/2010 a 2017/2018 de la hemeroteca de la página web del diario Marca. Las 18 crónicas corresponden a los siguientes partidos:

\begin{tabular}{|c|l|c|l|}
\hline Fecha & \multicolumn{1}{|c|}{ Resultado } & Fecha & \multicolumn{1}{c|}{ Resultado } \\
\hline 2009.09.26 & Real Madrid - C.D. Tenerife: 3-0 & 2010.02 .24 & Real Madrid - Villarreal C.F.: 6-2 \\
\hline 2010.11 .20 & Real Madrid - Ath. Bilbao: 5-1 & 2011.03 .12 & Real Madrid - Hércules C.F.: 2-0 \\
\hline 2011.12 .11 & Real Madrid - F.C. Barcelona: 1-3 & 2012.05 .13 & Real Madrid - Mallorca: 4-1 \\
\hline 2012.12 .16 & Real Madrid - Espanyol: 2-2 & 2013.04 .20 & Real Madrid - R. Betis: 3-1 \\
\hline 2013.09.22 & Real Madrid - Getafe C.F.: 4-1 & 2014.05 .04 & Real Madrid - Valencia C.F.: 2-2 \\
\hline 2014.09.13 & Real Madrid - At. Madrid: 1-2 & 2015.03 .15 & Real Madrid - Levante U.D.: 2-0 \\
\hline 2015.12.20 & Real Madrid - Rayo Vallecano: $10-2$ & 2016.03 .05 & Real Madrid - R.C. Celta: 7-1 \\
\hline 2016.11.26 & Real Madrid - Sporting Gijón: 2-1 & 2017.01 .29 & Real Madrid - Real Sociedad: 3-0 \\
\hline 2017.03.04 & Real Madrid - Málaga C.F.: 3-2 & 2018.02 .10 & Real Madrid - Real Sociedad: 5-2 \\
\hline
\end{tabular}

La herramienta usada en el análisis léxico es el programa AntConc, el cual proporciona una lista con las frecuencias léxicas de los textos sin lematizar y permite encontrar las concordancias de palabras concretas en el corpus textual. El análisis se limita a las palabras «que significan», esto es, las palabras con significado léxico autónomo, independiente de un contexto, y que pueden constituir núcleo del sintagma: sustantivos, adjetivos, verbos y adverbios (Ulrich 2002). El resto de palabras, con significado gramatical, no se contabiliza. 


\section{EL CONTENIDO LÉXICO-SEMÁNTICO FUNDAMENTAL DE LAS CRÓNICAS FUTBOLÍSTICAS DEL REAL MADRID}

El análisis cuantitativo del léxico de las 18 crónicas muestreadas ofrece un total de 11917 palabras gráficas (word tokens) y 2749 tipos léxicos (word types). Una vez eliminadas las palabras con significado gramatical, el corpus analizado contabiliza 5663 palabras gráficas (word tokens) y 2545 tipos léxicos (word types). La tabla siguiente muestra las 60 palabras con significado léxico más frecuentes del texto, incluidos los nombres propios de futbolistas.

\begin{tabular}{|c|c|c|c|c|c|c|c|c|}
\hline $\mathbf{N}^{0}$ & frec. & Palabra & $\mathbf{N}^{0}$ & frec. & palabra & $\mathbf{N}^{o}$ & frec. & palabra \\
\hline 1 & 168 & madrid & 11 & 26 & hizo & 21 & 17 & falta \\
\hline 2 & 67 & cristiano & 12 & 26 & minutos & 22 & 17 & ronaldo \\
\hline 3 & 64 & partido & 13 & 22 & blancos & 23 & 16 & bale \\
\hline 4 & 55 & equipo & 14 & 21 & mejor & 24 & 16 & barça \\
\hline 5 & 55 & real & 15 & 18 & defensa & 25 & 16 & сатро \\
\hline 6 & 48 & bernabéu & 16 & 18 & descanso & 26 & 16 & centro \\
\hline 7 & 45 & gol & 17 & 18 & remate & 27 & 16 & penalti \\
\hline 8 & 38 & benzema & 18 & 18 & rival & 28 & 16 & portugués \\
\hline 9 & 31 & goles & 19 & 18 & siempre & 29 & 16 & $v e z$ \\
\hline 10 & 29 & balón & 20 & 17 & blanco & 30 & 15 & liga \\
\hline
\end{tabular}

Como se observa, los términos más repetidos incluyen:

- Los que designan el club de fútbol: Madrid (168), en alusión a la ciudad del equipo, real (55), como parte del nombre del club, equipo (55), término general del mismo referente, blancos (22) y blanco (17), referido a los colores del equipo.

- Los nombres propios de los jugadores son muy frecuentes. Singular protagonismo tienen: Cristiano (67), acompañado por el apellido Ronaldo (17) o sustituido por su epíteto patronímico portugués (16) - Benzema (38), Bale (16).

- Los que designan la organización temporal del juego y la competición, y actúan como marcadores temporales de la narración: partido (64), minutos (26), descanso (18), siempre (18), vez (16), liga (15).

- Los referidos a las jugadas y lances del juego: gol (45), goles (31), remate (18), falta (17), penalti (16).

- Los que nombran el lugar del juego: Bernabeu (48), nombre del estadio, campo (16).

- Verbos de acción, como volvió (15). 
Del resto de los 60 tipos léxicos más frecuentes destacan los que designan al equipo contrario, rival (18), y a su máximo contrincante, Barça (16), mencionado en varias crónicas, aunque solo una de ellas trata de un partido entre el Real Madrid y el F.C. Barcelona. El objeto físico imprescindible para este juego, balón (29), también está presente. Se encuentra asimismo una de las formas verbales de pretérito perfecto simple de indicativo, típicas de la narración: hizo (26), así como el adjetivo calificativo en grado superlativo mejor (21). Hay, además, dos términos polisémicos: defensa ('jugador que defiende', 'acción de defender') y centro ('posición en la mitad del campo', 'lanzamiento del balón desde la parte lateral del campo al centro del ataque').

Del léxico más frecuente se concluye que las crónicas de los partidos de fútbol del Real Madrid giran en torno a información referente a este club y equipo, a sus jugadores más destacados, y a las acciones y movimientos con balón de estos sobre el campo, organizadas en los tiempos de la narración.

\section{LOS CONCEPTOS CENTRALES EN LAS CRÓNICAS FUTBOLÍSTICAS DEL REAL MADRID: CARACTERÍSTCAS LÉXICO-SEMÁNTICAS}

Los conceptos centrales de las crónicas futbolísticas analizadas coinciden con los tipos léxicos más frecuentes (véase supra). La alta frecuencia de los términos ejemplares, y su recurrencia a través de sinónimos y formas relacionadas, descubre las nociones sobre las que los periodistas sitúan el foco de atención.

Por limitaciones de espacio, nos ocuparemos solo de los cuatro conceptos centrales más frecuentes de estas crónicas. Estos son:

- 'equipo', con foco en el Real Madrid, que aparece en todas las crónicas Madrid $\left(1^{\circ}\right)$ es el tipo léxico más frecuente, con los tipos relacionados equipo $\left(4^{\circ}\right)$ y real $\left(5^{\circ}\right)$,

- 'jugador', con el foco sobre Cristiano Ronaldo, jugador estrella del equipo durante la época estudiada - Cristiano $\left(2^{\circ}\right)$ es el segundo tipo léxico más repetido,

- 'partido', evento deportivo al que se dedica cada crónica - partido $\left(3^{\circ}\right)$ es el tercer término más repetido,

- 'campo', lugar en el que se disputa el partido, apareciendo en todas las crónicas el estadio Santiago Bernabéu - Bernabéu $\left(6^{\circ}\right)$ es el tipo léxico recurrente aquí.

Como punto de referencia, en cada concepto partiremos de la definición del diccionario de fútbol de A. Nomdedeu Rull (2004: 711-786). 


\subsection{Equipo}

Este es un concepto central en una crónica deportiva, pues el fútbol es un deporte de equipo. Esa palabra se refiere al conjunto de los once jugadores en el campo, a los jugadores suplentes del banquillo, y, en un sentido más amplio, al club de fútbol como institución. El vocablo equipo define, según Nomdedeu Rull (2004: 741), al "conjunto de jugadores que compite en defensa de una misma entidad".

El equipo presente en todas las crónicas analizadas es el Real Madrid. Su denominación significa la entidad, la institución y el club, y por elipsis hace referencia al (equipo d)el Real Madrid. Las formas el Madrid (133), la más frecuente del corpus, y Real Madrid (55) identifican al equipo protagonista de estas crónicas.

En las crónicas de marca.com, los términos el Madrid y el Real Madrid son usados con una gran variedad de imágenes y usos idiomáticos de fuerza y violencia, tales como un boxeador contundente, una máquina que golpea, un toro bravo que acomete, una fuerza destructora, etc.:

Poco o nada tardó el Madrid en soltar un gancho que impactó de lleno en el Tenerife (26.09.09).

...un Real Madrid que es un martillo pilón (26.09.09).

El Real Madrid embiste de nuevo (24.11.10).

...el Madrid destrozó a un Mallorca que sólo creyó durante un minuto (13.05.12).

Por otra parte, el Madrid se muestra con características positivas de equipo acostumbrado a la victoria, que gana fácilmente, ejemplo de excelencia:

El Madrid ganó como siempre. Con una superioridad insultante (26.11.2016).

...el Real Madrid ganó con la gorra... (12.03.11).

El Real Madrid compendió en el último partido todas las virtudes que le han coronado como el mejor campeón de Liga de la historia (13.05.12).

Aunque el Madrid también aparece con rasgos negativos, ya que comete errores inoportunos, transmite desconfianza, hace reír y llorar a la vez:

El Madrid volvió a patinar en el peor momento (04.05.14).

...el Madrid volvió a dar una sensación de desasosiego alarmante (20.12.2015).

...el Madrid ya no es un equipo de fútbol normal, es una tragicomedia... (20.12.2015).

Mediante la sinécdoque los periodistas sustituyen el nombre del equipo por sus colores, blanco/s (39):

...pero eran los blancos los que corrían (11.12.11).

Doblete del luso en el triunfo blanco ante el Getafe (4-1) (22.09.13). 
Además, aparece merengue (5), metáfora que alude a la similitud con el color del postre de merengue, típico de las confiterías madrileñas.

...El festival merengue llegó en el segundo tiempo (21.02.10).

El término equipo (55) es connotado mediante diferentes estructuras sintácticas. Así, en 8 de las concordancias se utiliza el apellido del entrenador en un complemento del nombre para designar al equipo. En 7 ocasiones se alude al color blanco del Real Madrid. También se usa la oración adjetiva especificativa para mencionar características del equipo de fútbol:

...el equipo de Zidane se reveló impotente, desquiciado (25.11.17).

...pero esta vez el equipo blanco tenía la coartada del marcador (10.02.2018).

...al Athletic, un equipo que tiene las mismas agallas que el Madrid (20.11.10).

Los dos equipos enfrentados actúan uno como local (3), aquí el Madrid (168), y otro como visitante, con dos variantes léxicas para su denominación, rival/es (22) $\mathrm{y}$ visitante (5):

...el equipo local dio un paso atrás... (11.12.11).

...sometió a su rival a un asedio por momentos brutal (13.05.12).

...el visitante se adelantó demasiado pronto... (22.09.13).

Las formas conjunto (1), club (1), escuadra (1) casi no aparecen en el corpus.

\subsection{Jugador}

El término jugador se define como la "persona que forma parte de un equipo de fútbol" (Nomdedeu 2004: 752). La denominación de los jugadores se produce tanto a nivel individual, en torno a los jugadores destacados, como a nivel grupal, con designaciones que en el género gramatical femenino hacen referencia a un grupo de jugadores con la misma función, como la defensa (18).

A nivel individual, a los jugadores se les denomina mediante su apellido, su nombre de pila o su apodo, así como por metonimias tales como el número que portan en la camiseta, su nacionalidad o la función que desempeñan en el terreno de juego (Medina Cano 1995: 99; Nomdedeu 2004: 150). Según este uso periodístico, las designaciones más frecuentes en el corpus han sido los nombres de pila de las estrellas del equipo madridista: Cristiano (67), Benzema (38), Bale (16), etc. En segundo lugar, los jugadores han sido designados por sus posiciones tácticas y funciones sobre el terreno de juego: defensa (18) - con género masculino - delantero (9), portero/s (10). La mención de la nacionalidad ha sido otro modo de designación frecuente: portugués (16), brasileño (8), luso (6), argentino (4), etc. 
En el período analizado, el jugador más mediático en el Real Madrid era Cristiano Ronaldo. Su nombre es el segundo tipo léxico más frecuente: Cristiano (67). Las crónicas le adjudican una gran variedad de denominaciones.

\begin{tabular}{|l|l|l|}
\hline \multicolumn{1}{|c|}{ nombre de pila } & \multicolumn{1}{c|}{ nacionalidad } & \multicolumn{1}{c|}{ función } \\
\hline $\begin{array}{l}\text { Cristiano Ronaldo (4) } \\
\text { Cristiano (63) } \\
\text { Ronaldo (13) } \\
\text { CR9 (3) }\end{array}$ & $\begin{array}{l}\text { portugués (16) } \\
\text { luso (6) }\end{array}$ & $\begin{array}{l}\text { delantero (9) } \\
\text { nueve (4) }\end{array}$ \\
\hline
\end{tabular}

En la onomástica se utilizan uno o los dos nombres del jugador, con preferencia del primero. Es llamativa la composición de sus iniciales (CR) con el número 9, referido a su posición en el campo. A veces todas las denominaciones son reunidas en una sola frase, con información redundante, pues el 9 se refiere a la posición de delantero centro:

...un remate de 'nueve' del delantero portugués... (10.02.2018).

Con Cristiano se asocian numerosos epítetos elogiosos que lo ensalzan como dueño y señor del partido (21/02/10), insaciable (22/09/13), desatado (05/03/2016), majestuoso, espléndido (25/11/2017). A pesar de afirmarse literalmente que Cristiano reina en el Bernabéu (21/02/10), en las crónicas se critica con ironía su fuerte individualismo o se muestra su insatisfacción a pesar de la victoria del equipo:

$Y$ es que cuando Cristiano Ronaldo entiende que al fútbol juegan once es capaz de firmar partidos antológicos $(21 / 02 / 10)$.

El partido resultó especialmente frustrante para Cristiano, que se fue de vacio pese a participar de forma activa en los dos goles de su equipo (15.03.2015).

Por lo demás, para los diferentes jugadores, según su posición en el campo, se da la sinonimia, como entre portero y meta, o entre defensa y zaga. En otros casos, aparecen hipónimos que diferencian posiciones como laterales y centrales, ambos dentro de la defensa, o extremo, jugador de ataque por las bandas. Así aparecen:

- portero (8), meta (6),

- defensa/s (19), central/es (5), zaga (4), zaguero (1), lateral/es (7),

- delantero (9), ataque (5), atacantes (1), rematador (1).

Además, aparece la forma neutra jugador/es (10), con un uso extensivo y general, en contraste con las designaciones individuales:

El luso hizo lo que quiso con la frustrada defensa amarilla (21.02.10).

Se puede mirar a cualquier jugador menos a Cristiano (16.12.12).

...se metió entre los centrales blancos y les volvió literalmente locos... (16/12/12).

Un portero de broma para una defensa floja, de chiste (25.11.17). 


\subsection{Partido}

El término partido designa la "competición entre dos equipos con una duración de noventa minutos, dividida en dos partes de cuarenta y cinco minutos cada una" (Nomdedeu 2004: 764). El vocablo partido/s (71) es el tercer tipo léxico más frecuente del corpus de crónicas futbolísticas. También aparece el sinónimo encuentro/s (7), con ocurrencias como:

Así se llegó al final de un encuentro balsámico en el que sólo hubo pitos para Diarra... $(21 / 02 / 10)$.

El término partido aparece en una gran variedad de estructuras sintácticas:

- partido + adjetivo: seguido de un adjetivo calificativo que describe la calidad del partido: antológico, bueno, pleno, nuevo, plácido, terapéutico, oscuro, superlativo.

Aposición con sintagma nominal: un partido a puerta cerrada (10.02.18), sin público.

- partido + proposición subordinada adjetiva:

...un partido que retrata mejor sus virtudes que el del Getafe (22.09.13).

...que el Madrid no ganase un partido que no hizo esfuerzo por ganar (26.11.16).

- partido + sintagma preposicional adyacente:

El gol premiaba el buen partido de los de Pizzi... (04.05.14).

El partido de Ipurua reabre un debate... 'el partido jugado en Ipurua' (04.03.17).

- partido [Sujeto] $\rightarrow$ Predicado nominal:

El partido resultó especialmente frustrante para Cristiano (15.03.15).

El partido andaba finiquitado (10.02.18).

- partido [Sujeto] $\rightarrow$ Predicado verbal:

El partido dejó en un lugar especialmente delicado a Illarramendi (04.05.14).

El partido dio para múltiples lecturas (15.03.15).

- partido $[\mathrm{CD}] \leftarrow$ Verbo Predicativo:

Leo no necesitó goles para gobernar el partido (11.12.11).

...un recinto donde parecía jugarse un partido a puerta cerrada (10.02.18).

- partido [C.C.] $\leftarrow$ Verbo Predicativo:

El Tenerife se sabia la lección de memoria, organizado, enchufado en el partido (26.09.09).

...sigue saliendo a gol por partido (16.12.12). 
- de partido [Sujeto] $\leftarrow$ C.C. Tiempo:

...cuando faltaba más de media hora de partido (12.03.11).

...salvo en los primeros diez minutos de partido (04.05.14).

En cuanto a los verbos que funcionan como núcleos de predicados en los que partido es C.D., se da una amplia combinatoria con la siguiente casuística:

- jugar + el partido,

- arrancar, empezar, comenzar, iniciar + el partido,

- cerrar, finiquitar + el partido ['conseguir una diferencia de goles insalvable'],

- dominar, gobernar + el partido,

- dormir + el partido ['realizar un juego muy lento para frenar el ataque del rival'],

- ganar + el partido,

- meterse, entrar + en el partido ['comenzar a jugar según el plan previsto'].

\subsection{Campo}

El campo de fútbol se define como una "superficie rectangular de 90 a $120 \mathrm{~m}$. de longitud y de 45 a $90 \mathrm{~m}$. de ancho delimitada por las líneas de banda y las líneas de fondo para jugar al fútbol" (Nomdedeu 2004: 726). El término campo (16), no obstante, amplía su significado a otras acepciones, no solo como 'superficie sobre la que se juega al fútbol', en la que corren los jugadores y la pelota con designaciones relativas al césped, sino que también se refiere al estadio como edificio al que asisten los aficionados. De este modo, cuando se habla de jugar en campo propio, por asociación se trata del estadio que alberga el terreno de juego, y en el que se recibe el apoyo de la afición.

La distribución en el corpus de los términos relativos al concepto 'campo' es la siguiente: Bernabéu (46), Santiago Bernabéu (2), campo (16), estadio (5), casa (8), césped (6), terreno (3), pradera (1), verde (1). Como se observa, el procedimiento más utilizado es el de la designación por metonimia del campo con el nombre propio del estadio.

Aparecen las siguientes acepciones:

a) 'terreno de juego'

Es de agradecer que un equipo como el chicharrero pise el Bernabéu... (26.09.09).

El Athletic acabó pisoteado en la pradera del Santiago Bernabéu... (20.11.10).

...el mejor futbolista de los que pisaron el césped del Bernabéu... (16.12.12).

b) 'estadio'

...para que la música de viento retumbase en la acústica del Bernabéu (20.12.15).

...levantó el telón en el Bernabéu para empezar a mostrar su potencial... (26.11.16). 
...convertir al Bernabéu en un recinto donde parecía jugarse un partido a puerta cerrada (10.02.18).

c) 'afición'

En campo propio, volvió Pepe, perdonado por el Bernabéu (26.09.09).

...tiene enamorado al Bernabéu, estadio exigente que valora el esfuerzo... (20.11.10).

...despertando de su letargo a la adormecida grada del Bernabéu... (12.03.11).

Especialmente rico es el abanico de verbos usados cuando los términos que designan el campo o estadio toman el valor semántico de 'afición', el público que presencia el partido y que anima al equipo del Real Madrid. Así, se dice que el Bernabéu, como una persona, se encandila con las buenas jugadas y levanta el castigo a un jugador (22.09.13), y le perdona (26.09.09), que un fallo desata el enfado del Bernabéu (05.03.16), que la toma con el meta (13.09.14), que silva al equipo y se muestra frío (20.12.15), que una jugada devuelve al Bernabéu la sonrisa (29.01.17), que un jugador lo tiene enamorado (20.11.10), que otorga su aprobación (16.12.12), etc.

Se usa, además, la palabra casa (8) como 'campo propio', en tanto que la expresión fija casa blanca significa 'el club o la institución del Real Madrid':

...empatar en casa ante un rival abocado a pelear por la salvación... (26.11.16).

...un fantasma que amenaza con eternizarse en la Casa Blanca (11.12.11).

\section{CONCLUSIONES}

Hemos analizado el léxico de 18 crónicas deportivas, publicadas por la web del diario Marca, de partidos de fútbol disputados por el Real Madrid en su estadio entre 2009 y 2018. A través de un análisis de frecuencias léxicas y de concordancias, hemos identificado los conceptos fundamentales en relación con el Real Madrid y con el deporte del fútbol, y analizado las características léxico-semánticas de su actualización. Los tipos léxicos más frecuentes han señalado los conceptos sobre los que gira el contenido de la crónica. Los cuatro conceptos más repetidos son: 1) 'equipo' y los tipos léxicos (Real) Madrid y equipo, 2) 'jugador' y los tipos Cristiano (Ronaldo), 3) 'partido' y el tipo léxico partido, 4) 'campo' y el tipo léxico (Santiago) Bernabéu.

A continuación, hemos realizado un análisis detallado de las designaciones y el modo de significar de esos cuatro conceptos centrales. En el caso de equipo, el (Real) Madrid monopoliza estas crónicas, con connotaciones metafóricas y usos coloquiales de fuerza, valor y poder, de equipo ganador, con alusión metonímica a su color blanco. En cuanto a jugador, las crónicas focalizan, en especial, sobre la estrella del equipo, Cristiano (Ronaldo), aunque se mencionan otros jugadores usando tanto la onomástica como las designaciones de posiciones en el campo. 
Cristiano Ronaldo es designado mediante variantes de su nombre de pila, su nacionalidad o su función dentro del equipo, con asociaciones con matices de héroe épico, que subrayan su excelencia, y carácter individualista e inconformista. El término partido se presenta en una gran variedad de combinaciones sintácticas, tanto para describirlo y hablar de él (estructuras adjetivas y atributivas), como para ser objeto de la narración (estructuras predicativas). Estas últimas, en las que partido suele funcionar como C.D., descubren un elenco de verbos que típicamente se combinan en el lenguaje futbolístico con el vocablo partido. Finalmente, el término campo aparece fuertemente ligado al nombre que identifica el estadio del Real Madrid: Santiago (Bernabeu). Mediante la forma elíptica el Bernabéu, y por metonimia, adquiere los significados de otros términos asociados y cercanos a campo, como 'terreno de juego', 'estadio', 'afición'. Con esta última acepción, es muy frecuente el recurso de la personificación, lo que le da a la crónica carácter novelesco y dramático, a la vez. 


\section{BIBLIOGRAFÍA}

A.I.M.C.: Asociación para la Investigación de Medios de Comunicación. Resumen general de resultados EGM. Estudio General de Medios, 3 Año Móvil 2010, 2 Año Móvil 2018. Retrieved from: https://www.aimc.es/egm/datos-egm-resumen-general/.

Aleixandre-Benavent, R., Agulló Albuixech, R., Agulló Calatayud, V. \& Valderrama-Zurián, J.C. (2007). Terminología y lenguaje deportivo del fútbol. Cultura, Ciencia y Deporte, 2 (6), 117-123. DOI: $10.12800 /$ ccd.v2i6.179.

Álvarez Pedrosa, F. (2017). La crónica en el diario Marca antes y después de Internet. Análisis de la cobertura de la selección española de fútbol (1984-2008). Tesis doctoral. Valencia: Universidad CEU Cardenal Herrera.

Esteve Ramírez, F. \& Fernández del Moral, J. (1999). Áreas de especialización periodística. Madrid: Fragua.

Hernández Alonso, N. (2003). El lenguaje de las crónicas deportivas. Madrid: Cátedra.

Medina Cano, F. (1995). Los narradores deportivos y sus epopeyas cotidianas. Estudios sobre las Culturas Contemporáneas, 1, 2, 69-106.

Naranjo de Arcos, A. (2011). Tratamiento de la información deportiva en la prensa: la crónica como género prevalente. El caso de los encuentros de fútbol entre Real Madrid y F.C. Barcelona. Tesis doctoral. Málaga: Universidad de Málaga.

Nomdedeu Rull, A. (2004). Terminología del fútbol y los diccionarios: elaboración de un diccionario de especialidad para el gran público. Tesis doctoral. Barcelona: Universidad Autónoma de Barcelona.

Núñez Ladeveze, L. (1991). Manual para periodismo. Veinte lecciones sobre el contexto, el lenguaje y el texto de la información. Barcelona: Ariel.

Ulrich, W. (2002). Wörterbuch linguistische Grundbegriffe, 5. ed. Berlin/Stuttgart: Gebrüder Borntraeger. 